\title{
APLICABILIDADE DE UM PROTOCOLO FISIOTERÁPICO NO PÓS- OPERATÓRIO DE LIGAMENTO CRUZADO ANTERIOR
}

\author{
Weverthon Soares ${ }^{1}$; Walace Érick de Medeiros Moura ${ }^{2}$; Júlio Corrêa \\ Campos $^{2}$; Júlio Marco Soutelino Costa ${ }^{2} \&$ Juliano Silva França ${ }^{3}$
}

http://dx.doi.org/10.18571/acbm.008

${ }^{1}$ Acadêmica de fisioterapia na Universidade Iguaçu- Campus V- Itaperuna. RJ

${ }^{2}$ Professor do curso de Fisioterapia na Universidade Iguaçu- campus $\mathrm{V}$

${ }^{3}$ Coordenador do Curso de Fisioterapia da Universidade Iguaçu - C a $\mathrm{m} \mathrm{p} \mathrm{u} \mathrm{s} \mathrm{V}$

* autor para correspondência: weverthon-soares@ hotmail.com

\section{RESUMO}

O estudo teve como objetivo verificar a eficácia de um protocolo de tratamento na reabilitação de um pós-operatório de ligamento cruzado anterior do joelho com um individuo jovem e atleta do sexo masculino, que sofreu entorse do joelho esquerdo e apresentou ruptura parcial do ligamento cruzado anterior. No qual se observa uma melhora funcional significativa e gradativa a cada etapa do tratamento, o que mostrou a importância de um protocolo de tratamento no programa de reabilitação na reintegração funcional nas atividades de vida diárias deste indivíduo, que no caso especifico é um atleta jovem.

Palavra chave: ligamento cruzado anterior, protocolo, reabilitação.

\begin{abstract}
The study aimed to verify the effectiveness of a treatment protocol in the rehabilitation of a postoperative anterior cruciate ligament of the knee with an individual youngmale athlete, who suffered left knee sprain and partial rupture of the anterior cruciate ligament. In which we can observe a gradual and significant functional improvement at each stage of treatment, which showed the importance of a treatment protocol in the rehabilitation program on functional reintegration activities of daily living of this individual, who is a young athlete in this case.
\end{abstract}

Keyword: anterior cruciateligament, protocol, rehabilitation.

\section{1 - Introdução}

O Joelho é uma articulação de grande amplitude de movimento, suporta carga e se localiza na porção central do membro inferior. Formada por três superfícies articulares, os côndilos do fêmur, platô tibial e patela que realizam movimentos de rolamento, rotação interna, rotação externa e deslizamento. Mantida por ligamentos, meniscos e cápsulas que são estabilizadores estáticos; músculos e tendões que são estabilizadores dinâmicos. É uma articulação que está expostas a um grande índice de patologias de origem mecânica (HEBERT, et al, 1998).

O ligamento cruzado anterior (LCA), faz parte da articulação do joelho e impede a anteriorização da tíbia em relação ao fêmur, por ele ser o ligamento mais fraco em comparação ao ligamento cruzado posterior é mais freqüente a lesão e se origina-se na área 
intercondilar anterior da tíbia, e se fixa à parte posterior da face medial do côndilo lateral do fêmur (MOORE, 2007).

Entorse do ligamento cruzado anterior é a lesão mais comum de ser encontrada. Sua estrutura anatômica torna-o predisposto à lesão tanto por mecanismos sem contato e por contato. A lesão por contato pode ocorrer quando o joelho esta na posição de hiperextensão por uma força externa. O ligamento cruzado anterior é tracionado e tensionado, sofrendo um cisalhamento. A lesão sem contato é observada quando um corredor desacelera bruscamente como no futebol, lateralmente enquanto seu pé está fixo no chão. "Isto leva o joelho a uma postura em valgo, à medida que a tíbia é rodada lateralmente sobre o fêmur." E em seguida um estalo é ouvido pelo indivíduo (KONIN, 2006).

Este estudo é um relato de caso de um jovem atleta que teve lesão do ligamento cruzado anterior e que após procedimento cirúrgico procurou atendimento fisioterápico na Clínica Escola de Fisioterapia da Universidade Iguaçu (UNIG) - Campus V- Itaperuna - Rj, na qual foi aplicado um protocolo fisioterápico no pós - operatório de ligamento cruzado anterior durante 30 dias.

\section{2 - Materiais e Métodos}

\section{1 - Método de Avaliação}

Paciente L.M.S, 16 anos, estudante, atleta, $73 \mathrm{~kg}$ de peso, $1.73 \mathrm{~cm}$ de altura, no dia $22 \mathrm{de}$ Dezembro de 2010 durante uma partida de futebol o paciente deu um arranque com o joelho rodado quando então ouviu um estalo no joelho esquerdo acompanhado de dor e edema, não procurou um ortopedista em casa mesmo colocava gelo todos os dias. Um mês depois viu que estava melhorando voltou a treinar. Durante o treinamento quando firmou o pé no chão com o joelho completamente estendido e com o outro pé bateu na bola quando então ouviu um estalido no joelho esquerdo acompanhado de dor e edema. Logo após foi encaminhado ao ortopedista que foi constatado que o ligamento cruzado anterior estava rôto que indicou crioterapia e repouso.

Paciente compareceu na clínica escola de Fisioterapia no dia 15 de Setembro de 2011 com o diagnostico clinico de pós-operatório de ruptura parcial de LCA. Apresentando ao exame físico quadro álgico só durante a palpação e cicatriz em região medial do joelho esquerdo, edema em região do joelho esquerdo, bloqueio funcional para flexão e extensão completa no joelho esquerdo. Foram realizados também o teste manual de força muscular dos músculos quadríceps, isquiotibiais, abdutores e adutores do quadril, gastrocnêmios e perimetria de coxa e perna.

No primeiro dia de tratamento paciente apresentou força muscular no membro operado: Grau 3: extensão do joelho (Quadríceps) e flexão do joelho (Isquiotibiais).

Grau 5: flexão plantar do tornozelo (Gastrocnêmios), abdutores (Glúteo médio e tensor da fáscia lata) e adutores do quadril.

Membro sadio apresentou Grau 5 em todos os parâmetros.

A escala utilizada está demonstrada na tabela 1: 


\begin{tabular}{lll}
\hline \multicolumn{4}{c}{ Sistema de graduação de teste muscular manual } \\
\hline Amplitude completa contra resistência \\
6 & NA acima do normal & com resistência máxima \\
5 & N normal & com resistência considerável \\
4 & B bom & com alguma resistência
\end{tabular}

Amplitude completa de movimento
$3 \mathrm{R}$ regular
contra gravidade
$2 \mathrm{~F}$ fraco
com ausência de gravidade

Sem amplitude de movimento
$\begin{array}{llll}1 & \mathrm{~T} & \text { traço } & \text { leve contração } \\ 0 & 0 & \text { zero } & \text { sem contração }\end{array}$

Modificado de Daniels L and Worthingham C: Therapeutic

Exercise, ed 2, Philadelphia, 1977, WB Saunders; and

Kendall HO, Kendall FP, and Wadsworth GE: Muscles:

Testing and function, ed 2, Baltimore, 1971, Williams \& Wilkins.

Tab. 1 - Sistema de graduação de teste muscular manual. Fonte: (GOULD III, 1993)

O teste articular foi medido de forma ativa a amplitude de movimento através do goniômetro de régua que constatou no primeiro dia do tratamento $60^{\circ}$ de flexão ativa do joelho e extensão completa no joelho operado. Joelho sadio apresentou $120^{\circ}$ de flexão ativa e extensão completa.

Foi realizado a perimetria de coxa e perna com fita métrica medindo a circunferência para verificar a diminuição do diâmetro do segmento operado. O ponto de referência utilizado foi o bordo superior da patela detalhado de 5 à $20 \mathrm{~cm}$ e bordo inferior da patela de 5 à $15 \mathrm{~cm}$. O paciente no primeiro dia de avaliação apresentou:

\begin{tabular}{cccccc}
\hline COXA & Direita & Esquerda & PERNA & Direita & Esquerda \\
\hline $\mathbf{5} \mathbf{~ c m}$ & 45 & 42,5 & $\mathbf{5} \mathbf{~ c m}$ & 37 & 36,5 \\
$\mathbf{1 0} \mathbf{~ c m}$ & 50 & 47,5 & $\mathbf{1 0} \mathbf{~ c m}$ & 39,5 & 38,5 \\
$\mathbf{1 5} \mathbf{~ c m}$ & 55 & 51,5 & $\mathbf{1 5} \mathbf{~ c m}$ & 38 & 37 \\
$\mathbf{2 0} \mathbf{~ c m}$ & 58,5 & 54 & & & \\
\hline \multicolumn{5}{c}{ Tab. 2 - Perimetria do Paciente no $1^{\mathbf{0}}$ dia. }
\end{tabular}

\section{2 - Método de Tratamento}

Foi utilizado e adaptado o protocolo de tratamento de JORGE e DUARTE, 2007.

\section{Condutas de tratamento do $1^{\circ}$ ao $5^{\circ}$ dia}

Paciente apresentou-se com $60^{\circ}$ de flexão do joelho, edema e quadro álgico na palpação. 
Laser - $904 \mathrm{~nm}$ (arseneto de gálio) : Com a técnica pontual sobre a cicatriz na região ânterio-medial do joelho esquerdo e nos pontos da artroscopia. Dosimetria $-4 \mathrm{j} / \mathrm{cm}^{2} 20$ disparos de 12 segundos. Crioterapia em posição de drenagem, Artrocinemática e osteocinemática para o ganho de flexão do joelho à partir de $60^{\circ}$ e Mobilização da patela.

\section{Condutas de tratamento do $6^{\circ}$ ao $10^{\circ}$ dia}

Nesta fase paciente obteve ganho de flexão do joelho de $100^{\circ}$ e abolição do edema.

Foram mantidos: Laser pontual, Crioterapia com a técnica panqueca de gelo, Artrocinemática e osteocinemática com $100^{\circ}$ de flexão do joelho.

Foram acrescidos: Tração do joelho com $45^{\circ}$ para hipomobilidade de flexão, Alongamento do retináculo lateral e medial da patela, Alongamento do quadríceps, isquiostibiais, iliopsoas, gastrocnêmios, sóleo e adutores e abdutores do quadril para ganho de elasticidade muscular e Fortalecimento muscular dos flexores, extensores, adutores e abdutores do quadril em cadeia cinética aberta para o ganho de resistência muscular com thera-band cinza.

\section{Condutas de tratamento do $11^{\circ}$ ao $15^{\circ}$}

Nesta fase paciente apresentou ganho de flexão de $120^{\circ}$.

Foram mantidos: Crioterapia com técnica panqueca de gelo, Tração do joelho a $45^{\circ}$, Artrocinemática e osteocinemática para ganho da flexão do joelho. Todos alongamentos anteriores foram mantidos.

Foram acrescidos: Massagem transversal profunda, Exercícios de fortalecimento com resistência manual para quadríceps e iquiotibiais na proporção de 2:1 (2 para flexão e 1 para extensão), Fortalecimento muscular do quadríceps, isquiostibiais, abdutores e adutores do quadril em cadeia cinética aberta para o ganho de potência muscular com caneleira de $2 \mathrm{~kg}$ e Reeducação sensorial-motora de baixo impacto através do trabalho de toques.

\section{Condutas de tratamento do $16^{\circ}$ ao $19^{\circ}$ dia}

Nesta fase continua com angulação de $120^{\circ}$ de flexão ativa do joelho e nesta fase também foi realizada a goniômetria passiva que apresentou $135^{\circ}$.

Foram mantidas: Crioterapia, tração do joelho, artrocinemática e osteocinemática, alongamentos anteriores citados e Fortalecimento anteriores citados com caneleira de $3 \mathrm{~kg}$

Foram acrescentados: Propriocepção em solo rígido com médio impacto.

\section{Condutas de tratamento do $20^{\circ}$ ao $24^{\circ}$ dia}

Nesta fase continua com angulação de $120^{\circ}$ de flexão ativa e $139^{\circ}$ de flexão passiva.

Foram mantidos: Alongamento anteriores citados e Fortalecimento anteriores citados só que agora com a caneleira de $4 \mathrm{~kg}$ em cadeia cinética aberta.

Foram acrescidos: Facilitação neuromuscular proprioceptiva para o ganho do final do arco de movimento para flexão e rotação medial do joelho, Propriocepção inconsciente na cama elástica trabalhando as aferências visuais e Propriocepção inconsciente com uso de bola.

\section{Condutas de tratamento do $25^{\circ}$ ao $30^{\circ}$ dia}

Nesta fase o arco de movimento para flexão do joelho era completa. De $120^{\circ}$ de flexão ativa e $140^{\circ}$ de flexão passiva, em relação ao membro não operado.

Foram mantidos: Facilitação neuromuscular proprioceptiva para o ganho de arco de movimento ( apenas para manutenção do arco. Porque em comparação com a perna sabia apresenta a mesma angulação) e Alongamentos anteriores citados.

Foram acrescentados: Corrente Russa para melhorar trofismo muscular em quadríceps e ísquios (Frequencia $=20 \mathrm{hz}$

Trêm de pulso $=50 \%,($ Rise (s) 2,On (s) 4, Decay $(\mathrm{s}) 16$, 
Off (s) 2), 20 minutos, modo sincronizado) A corrente russa foi associada ao exercício com caneleira de $5 \mathrm{~kg}$ para recrutar mais fibras musculares e com isso ganhar mais massa, Propriocepção na cama elástica com exercício pliométricos.

\section{3 - Resultados}

Os resultados analisados neste estudo foram o da perimetria, da goniômetria e do grau de força muscular.

\section{Grau de força muscular}

No primeiro dia o individuo apresentou grau 3 na extensão e flexão do joelho esquerdo (operado) e grau 5 na abdução e adução de quadril esquerdo. No vigésimo quinto dia apresentou grau 5 para extensão e flexão do joelho esquerdo (operado) e manteve na abdução e adução de quadril esquerdo.

\section{Goniômetria}

Goniômetria para flexão do joelho

\begin{tabular}{cc}
\hline $\mathbf{1}^{\circ}$ ao $5^{\circ}$ dia & $60^{\circ}$ (Ativa) \\
\hline $\mathbf{6}^{\circ}$ ao $10^{\circ}$ dia & $100^{\circ}$ (Ativa) \\
$\mathbf{1 1}^{\circ}$ ao $\mathbf{1 5}^{\circ}$ dia & $120^{\circ}$ (Ativa) \\
$\mathbf{1 6}^{\circ}$ ao $\mathbf{1 9}^{\circ}$ dia & $120^{\circ}$ (Ativa) e $135^{\circ}$ (Passiva) \\
$\mathbf{2 0}^{\circ}$ ao $\mathbf{2 4}^{\circ}$ dia & $120^{\circ}$ (Ativa) e $139^{\circ}$ (Passiva) \\
$\mathbf{2 5}^{\circ}$ ao $30^{\circ}$ dia & $120^{\circ}$ (Ativa) e $140^{\circ}$ (Passiva) \\
\hline
\end{tabular}

Tab. 3 - Goniômetria do Paciente.

\section{Perimetria}

\begin{tabular}{cccccc}
\hline COXA & Direita & Esquerda & PERNA & Direita & Esquerda \\
\hline $\mathbf{5} \mathbf{~ c m}$ & 45 & 42,5 & $\mathbf{5} \mathbf{~ c m}$ & 37 & 36,5 \\
$\mathbf{1 0} \mathbf{~ c m}$ & 50 & 47,5 & $\mathbf{1 0} \mathbf{~ c m}$ & 39,5 & 38,5 \\
$\mathbf{1 5} \mathbf{~ c m}$ & 55 & 51,5 & $\mathbf{1 5} \mathbf{~ c m}$ & 38 & 37 \\
$\mathbf{2 0} \mathbf{~ c m}$ & 58,5 & 54 & & & \\
\hline
\end{tabular}

Tab. 4 - Perimetria do Paciente no $1^{\circ}$ dia.

\begin{tabular}{cccccc}
\hline COXA & Direita & Esquerda & PERNA & Direita & Esquerda \\
\hline $\mathbf{5} \mathbf{~ c m}$ & 45 & 43,5 & $\mathbf{5} \mathbf{~ c m}$ & 37 & 36,5 \\
$\mathbf{1 0} \mathbf{~ c m}$ & 50 & 48,5 & $\mathbf{1 0} \mathbf{~ c m}$ & 39,5 & 38,5 \\
$\mathbf{1 5} \mathbf{~ c m}$ & 55 & 52,5 & $\mathbf{1 5} \mathbf{~ c m}$ & 38 & 37 \\
$\mathbf{2 0} \mathbf{~ c m}$ & 58,5 & 55 & & & \\
\hline
\end{tabular}

Tab. 5 - Perimetria do Paciente no $1^{\circ}$ mês.

\section{4 - Conclusão}

Conclui-se que o protocolo que foi aplicado para tal paciente obteve respostas satisfatória no controle da dor, no controle do edema e principalmente no ganho de amplitude de movimento (ADM) nos primeiros trinta dias de tratamento. Vale ressaltar também que este protocolo tem uma duração de oito meses, mas devido a resposta positivas do organismo do paciente tratado permitiu já iniciar o processo de fortalecimento muscular e propriocepção. 
Portanto, após a reconstituição do ligamento cruzado anterior a fisioterapia é uma forma indispensável de tratamento, principalmente se aplicar o programa de reabilitação funcional apropriada ao paciente objetivando o retorno do indivíduo às suas atividade do cotidiano e as suas atividades física o mais rápido possível, além de diminuir os riscos de complicações após tratamento.

5 - Referências Bibliográficas

HEBERT, S.; XAVIER, R.; PARDINI - JR, A. G.; BARROS FILHO, T. E. P. Ortopedia e Traumatologia Princípios e Prática. 2a Edição. Porto Alegre: Editora Artmed. 1998

MOORE, K. L.; DALLEY, A. F. Anatomia Orientada para a Clínica. $5^{a}$ Edição. Rio de Janeiro: Editora Guanabara Koogan. 2007

KONIN, J. G. Cinesiologia Prática para Fisioterapeutas. $1^{\text {a }}$ Edição. Rio de Janeiro: Editora Guanabara Koogan. 2006

JORGE, Matheus da Cunha; DUARTE, Marcelo Silva. Reabilitação funcional do joelho pós ligamentoplastia do ligamento cruzado anterior do joelho. Um estudo de Caso. www.frasce.edu.br. Lisboa Portugal.2007

GRAY, H. Gray Anatomia. 37ª Edição. Rio de Janeiro: Editora Guanabara Koogan. 1995

ROSSE, C.; GADDUM - ROSSE, P. Tratado de Anatomia. $5^{\text {a }}$ Edição. Rio de Janeiro: Editora Revinter. 1997

GOULD III, J. A. Fisioterapia na Ortopedia e na Medicina do Esporte. $2^{a}$ Edição. São Paulo: Editora Manole. 1993

KAPANDJI, A. I. Fisiologia Articular do Membro Inferior. $5^{\text {a }}$ Edição. Rio de Janeiro: Editora Guanabara Koogan. 2000 